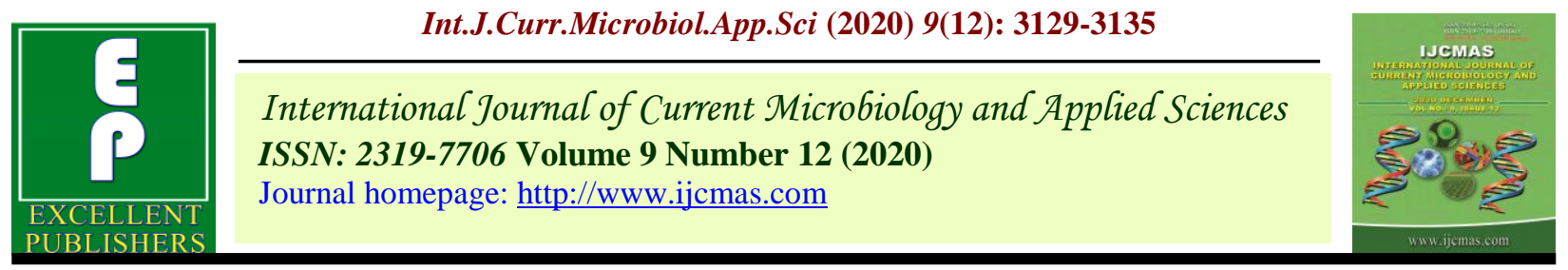

Original Research Article

https://doi.org/10.20546/ijcmas.2020.912.372

\title{
Development of Carrot Juice Concentrate Enriched Functional Cookies
}

\author{
Sakshi Sharma* and K. D. Sharma \\ Department of Food Science and Technology, Dr YS Parmar University of Horticulture and \\ Forestry, Solan, HP. India \\ *Corresponding author
}

\section{A B S T R A C T}

\section{Keywords}

Carrot juice

Concentrate,

Functional cookies

Article Info

Accepted:

27 November 2020

Available Online:

10 December 2020
This study was conducted to investigate the potential of utilization of carrot juice concentrate for the preparation of functional cookies. Cookies were supplemented with different levels of carrot juice concentrate $(5,10,15,20$ and 25\%) and best treatment was selected on the basis of sensory evaluation. The best treatment was further examined for various physico-chemical parameters. It was observed that addition of carrot juice concentrate has improved the functional properties of cookies without compromising the sensory qualities. Cookies prepared with 15 per cent carrot juice concentrate were adjudged best by the panelists in terms of sensory score i.e. color (8.15), texture (8.12), taste (7.98) and overall acceptability (8.10). The study suggested that carrot juice concentrate can be successfully be utilized in development of nutritionally and functionally enriched cookies.

\section{Introduction}

Carrot (Daucuscarota sativus) is one of the most important seasonal root vegetable belonging to family Apiaceae (Umbelliferae) and is grown extensively in India during winter season for its edible taproot. It is considered to be native of Afghanistan (Banga, 1957). The earliest known mention of domesticated carrots dates back to the 10th century in Persia and Asia Minor; then it spreads to all Asia, Europe, North Africa and the Mediterranean region (Kalra et al., 1987; Mazza, 1989). Nutritionally, carrot is rich in both antioxidants i.e. lipophilic (xanthophylls, carotenoids) and hydrophilic (phenols), vitamin $\mathrm{A}, \mathrm{B}_{1}, \mathrm{~B}_{2}, \mathrm{C}, \mathrm{E}$, folic acid, flavonoids, phosphorus and extraordinary pectin fibers (Sharma et al., 2012; Aadil et al., 2013; Leja et al., 2013; Mazzoni et al., 2016; Kaur et al., 2018). Carotenes which is the major pigment present in carrot and a well-known precursor of vitamin A, have long been recognized for their role in vision, cataract prevention but more recently claims has been made for its anti-cancer properties and its role in prevention of cardiovascular diseases (Breithaupt and Bamedi, 2001). Carrots are consumed as raw (fresh, whole or baby carrots) and processed or manufactured form (canned foods, soups, juice and frozen products). One of the most important processed forms is carrot juice which is natural source of antioxidants along with 
other nutritional qualities as well. Therapeutic properties of carrot juice include boosting of immunity, minor wound and injury healing and maintaining normal blood pressure. It also cleans the liver by excreting fats and bile (Bahkru, 1993; Wrolstad, 2004). Because of all these properties, carrot juice is often considered as a health drink or super food. Moreover, the natural single strength juice is in such a huge volume (84-91 \% moisture content) that their packaging, storage or transportation is very expensive from an economical point of view. To overcome these challenges and to ensure supply of nutritionally rich juice or its products around the year, the volume of juices is often reduced with a process, commonly known as "fruit juice concentration". In this process, a major part of naturally present water content is physically removed (Jeong et al., 2004). The developed carrot juice concentrate is therefore a concentrated source of phytonutrients and it can be utilized for the enrichment of bakery products. Therefore, this study was conducted for the development of carrot juice concentrate enriched functional cookies.

\section{Materials and Methods}

\section{Raw material}

Carrots were procured from local fruit and vegetable market, Solan, Himachal Pradesh and brought immediately to the fruit processing unit of Department of Food Science and Technology for further studies. The other material such as refined wheat flour, sugar, salt, baking powder, fat and polyethylene pouches etc. were procured from local market at Solan.

\section{Preparations of carrot juice concentrate}

Carrot roots were washed under running water, trimmed using stainless steel knife and dirty skin along with undesirable hair was removed. Juice was extracted with the help of mechanical juice extracted. The juice was further preserved by heat processing till further utilization. Concentration of juice was held in vacuum rotary evaporator upto desired concentration.

\section{Standardization of different proportion}

For preparation of cookies, standard method described by Vanlallini, (2019) with some modifications was used and formulations of cookies shown in Fig. 1. The ingredients such as refined wheat flour $(100 \mathrm{~g})$, vegetable ghee $(40 \mathrm{~g})$, powdered sugar $(35 \mathrm{~g})$, skim milk powder $(10 \mathrm{~g})$, salt $(0.75 \mathrm{~g})$ and sodium bicarbonate $(1 \mathrm{~g})$ were used to prepare the cookies. The powdered sugar was mixed with vegetable ghee and the mixture was beaten until light and fluffy. The sieved refined wheat flour and sodium bicarbonate along with salt and skimmed milk powder were added to the fluffy mass and mixed thoroughly to form soft dough. In case of functionally enriched cookies, carrot juice concentrate was used instead of water for the preparation of dough (Table 1). The mixture was kneaded properly for about 10 minutes and wrapped in an aluminium foil. The dough was allowed to stand at room temperature for about 30 minutes and after that it was converted into small balls. The balls were flattened into sheet of about $0.6 \mathrm{~cm}$ thickness. The flattened sheet was cut into circular shapes with the help of cookie cutter having diameter of $4.0 \mathrm{~cm}$. The cut shapes were placed on a baking tray lined with butter paper and baked in an oven at $200^{\circ} \mathrm{C}$ for 20 minutes. The best treatment/ combinations were selected based on sensory evaluation for further studies.

\section{Physico-chemical and sensory evaluation}

The control and best rated samples were evaluated for their physico-chemical 
characteristics viz. total sugars, reducing sugars, ascorbic acid, total phenols and total carotenoids as per the standard analytical methods (Ranganna, 2009). Antioxidant activity (Free radical scavenging activity) of the samples was measured as per the method of Brand- Williams et al., (1995) by using DPPH (2, 2-diphenyl- 1-picrylhydrazyl) as a source of free radical. Sensory evaluation of the product was conducted by a panel of ten judges using 9- point hedonic scale system for different parameters viz. appearance, body, flavor and overall acceptability (Amerine et al., 1965).

\section{Statistical analysis}

All the analytical parameters were recorded in triplicates and the mean values of each parameter were described with standard error (SE). The data pertaining to quantitative estimation of physico-chemical characteristics were assessed by factorial CRD by Cochran and Cox (1967), whereas Randomized Complete Block Design (RBD) as described by Mahony (1985) was used to analyze the data pertaining to sensory evaluation.

\section{Results and Discussion}

\section{Optimization of carrot juice concentrates for the preparation of functionally enriched cookies}

The effects of addition of different levels of carrot juice concentrate on sensory attributes of the developed cookies are presented in Table 2. It was observed that with the increase in the proportions of carrot juice concentrate up to 25 per cent the score for colour increased. However, the texture score was increased upto 15 per cent addition, beyond which it decreased due to changes in various physical characteristics of cookies. The highest colour score (8.20) was obtained by Treatment $\mathrm{T}_{5}(25 \%)$ which was statistically at par with treatment $\mathrm{T}_{3}(15 \%$ carrot juice concentrate) andT $\mathrm{T}_{4} \quad(20 \%$ carrot juice concentrate). The sensory score for texture indicated that the maximum score was obtained by treatment $\mathrm{T}_{3}$ (8.12) having 15 per cent carrot juice concentrate (Fig. 2). It is evident from the data that flavour score for different treatments varied from 7.79 to 7.98 with maximum score obtained by the treatment $\mathrm{T}_{3}$ (15\% carrot juice concentrate). Similar results were also recorded for overall acceptability (Table 2). Addition of carrot juice concentrate in appropriate proportion might have enhanced the flavour profile of the product and hence rated highest by the panelist on the basis of overall acceptability of the cookies. Similar results were reported by Kumar and Kumar (2011) in carrot pomace and wheat flour based cookies. Similar results were reported by Kumar et al., (2010), Sahni and Shere (2017), Ukeyina et al., (2019) and Dinnah et al., 2020.

\section{Physical, chemical and functional characteristics}

The physical, chemical and functional characteristics of cookies with refined wheat flour $\left(\mathrm{T}_{0}\right)$ and supplemented with carrot juice concentrate $\left(\mathrm{T}_{1}\right)$ are depicted in Table 3. The cookies of $\mathrm{T}_{0}$ and $\mathrm{T}_{1}$ possessed a weight $(\mathrm{g})$ of $12.40 \pm 0.15$ and $12.34 \pm 0.10$, diameter $(\mathrm{cm})$ $3.87 \pm 0.06$ and $3.76 \pm 0.05$, thickness $(\mathrm{cm})$ $1.05 \pm 0.01$ and $1.01 \pm 0.02$, respectively. The spread ratio of $\mathrm{T}_{0}$ (control) cookies was 3.68 \pm 0.04 which increased with addition of carrot juice concentrate to $3.72 \pm 0.05$ in $\mathrm{T}_{1}(15 \%$ carrot juice concentrate). It was in agreement with the reports of Mounika and Maloo (2018) who prepared fibre rich cookies by substituting refined wheat flour with carrot pomace powder (CPP) and reported increase in weight, thickness, moisture, crude fibre and ash content of the cookies, whereas the diameter, spread ratio, spread factor, protein and carbohydrate decreased with the increase 
in CPP in flour blend. Similar results were also observed by Sahni and Shere (2017).

The data presented in Table 4 revealed that the addition of carrot juice concentrate had improved nutritional quality of cookies as evident from its higher total phenolic content $(15.85 \mathrm{mg} / 100 \mathrm{~g})$, ascorbic acid content $(5.12$ $\mathrm{mg} / 100 \mathrm{~g})$, carotenoids $(8.37 \mathrm{mg} / 100 \mathrm{~g})$ and antioxidant potential $(35.69 \%$ free radical scavenging activity) compared to standard cookies $(4.21 \mathrm{mg} / 100 \mathrm{~g}$ phenolic content, 1.23 $\mathrm{mg} / 100 \mathrm{~g}$ ascorbic acid, $0.32 \mathrm{mg} / 100 \mathrm{~g}$ carotenoids and $5.54 \%$ free radical scavenging activity). The results were in conformity with Nagarajaiah and Prakash (2015) in carrot pomace incorporated cookies. The higher nutritional value of cookies with addition of carrot was also reported by Turksoy et al., (2011), Cho and Chung (2019), Ahure and Ejaha (2020).

Table.1 Detail of treatment for the preparation of carrot juice enriched functional cookies

\begin{tabular}{|l|c|}
\hline Treatment & Carrot juice concentrate (\%) \\
\hline $\mathbf{T}_{\mathbf{0}}$ & 0 \\
\hline $\mathbf{T}_{\mathbf{1}}$ & 5 \\
\hline $\mathbf{T}_{\mathbf{2}}$ & 10 \\
\hline $\mathbf{T}_{\mathbf{3}}$ & 15 \\
\hline $\mathbf{T}_{\mathbf{4}}$ & 20 \\
\hline $\mathbf{T}_{\mathbf{5}}$ & 25 \\
\hline
\end{tabular}

Table.2 Sensory evaluation of carrot juice concentrate enriched functional cookies

\begin{tabular}{|l|c|c|c|c|}
\hline \multicolumn{1}{|c|}{ Treatment } & Color & Texture & Taste & Overall acceptability \\
\hline $\mathbf{T}_{\mathbf{0}}(\mathbf{C o n t r o l )}$ & $\mathbf{7 . 8 5}$ & $\mathbf{7 . 8 4}$ & $\mathbf{7 . 7 9}$ & $\mathbf{7 . 7 5}$ \\
\hline $\mathbf{T}_{\mathbf{1}}(\mathbf{5 \%} \mathbf{C J C})$ & 8.03 & 7.90 & 7.83 & 7.82 \\
\hline $\mathbf{T}_{\mathbf{2}}(\mathbf{1 0 \%}$ CJC) & 8.09 & 8.03 & 7.87 & 7.87 \\
\hline $\mathbf{T}_{\mathbf{3}}(\mathbf{1 5 \%}$ CJC) & $\mathbf{8 . 1 5}$ & $\mathbf{8 . 1 2}$ & $\mathbf{7 . 9 8}$ & $\mathbf{8 . 1 0}$ \\
\hline $\mathbf{T}_{\mathbf{4}}(\mathbf{2 0 \%}$ CJC) & 8.17 & 8.05 & 7.85 & 7.86 \\
\hline $\mathbf{T}_{\mathbf{5}}(\mathbf{2 5 \%} \mathbf{C J C})$ & 8.20 & 8.10 & 7.80 & 7.79 \\
\hline $\mathbf{C D}_{(\mathbf{0 . 0 5}}$ & 0.05 & 0.06 & 0.08 & 0.07 \\
\hline
\end{tabular}

*Sensory evaluation on 9-point Hedonic scale: 9=like extremely, 1=dislike extremely $\mathrm{CJC}=$ Carrot juice concentrate

Table.3 Physical characteristics of cookies (control) and best rated carrot juice enriched functional cookies

\begin{tabular}{|l|c|c|}
\hline \multirow{2}{*}{ Characteristics } & \multicolumn{2}{|c|}{ Mean \pm SE } \\
\cline { 2 - 3 } & $\mathbf{T}_{\mathbf{0}}$ (Control) & $\mathbf{T}_{\mathbf{2}}(\mathbf{1 5 \%} \mathbf{C J C})$ \\
\hline Weight $\mathbf{( g )}$ & $12.40 \pm 0.15$ & $12.32 \pm 0.10$ \\
\hline Diameter $(\mathbf{c m})$ & $3.87 \pm 0.06$ & $3.76 \pm 0.05$ \\
\hline Thickness $(\mathbf{c m})$ & $1.05 \pm 0.01$ & $1.01 \pm 0.02$ \\
\hline Spread ratio & $3.68 \pm 0.04$ & $3.72 \pm 0.05$ \\
\hline
\end{tabular}

*Each value is average of three determinations; $\mathrm{SE}=$ Standard error 
Table.4 Chemical characteristics of cookies (control) and best rated carrot juice enriched functional cookies

\begin{tabular}{|l|c|c|}
\hline \multirow{2}{*}{ Characteristics } & \multicolumn{2}{c|}{ Mean \pm SE } \\
\cline { 2 - 3 } & $\mathbf{T}_{\mathbf{0}}($ Control) & $\mathbf{T}_{\mathbf{2}}(\mathbf{1 5 \%} \mathbf{C J C})$ \\
\hline Water activity & $0.40 \pm 0.02$ & $0.44 \pm 0.01$ \\
\hline Moisture (\%) & $4.28 \pm 0.11$ & $4.41 \pm 0.09$ \\
\hline Ash (\%) & $0.71 \pm 0.02$ & $0.85 \pm 0.03$ \\
\hline Protein (\%) & $8.37 \pm 0.17$ & $8.40 \pm 0.12$ \\
\hline Fat (\%) & $19.43 \pm 0.73$ & $18.14 \pm 0.85$ \\
\hline Total sugars (\%) & $23.84 \pm 1.45$ & $25.10 \pm 1.23$ \\
\hline Reducing sugars (\%) & $9.65 \pm 0.26$ & $10.64 \pm 0.31$ \\
\hline Ascorbic acid (mg/ 100g) & $1.23 \pm 0.04$ & $5.12 \pm 0.06$ \\
\hline Carotenoids (mg/ 100g) & $0.32 \pm 0.01$ & $8.37 \pm 0.05$ \\
\hline Total phenolic content (mg/ 100g) & $4.21 \pm 0.03$ & $15.85 \pm 0.08$ \\
\hline Antioxidant activity (\% free radical scavenging activity) & $5.54 \pm 0.13$ & $35.69 \pm 0.16$ \\
\hline
\end{tabular}

*Each value is average of three determinations; $\mathrm{SE}=$ Standard error

Fig.1 Unit operations for preparation of cookies

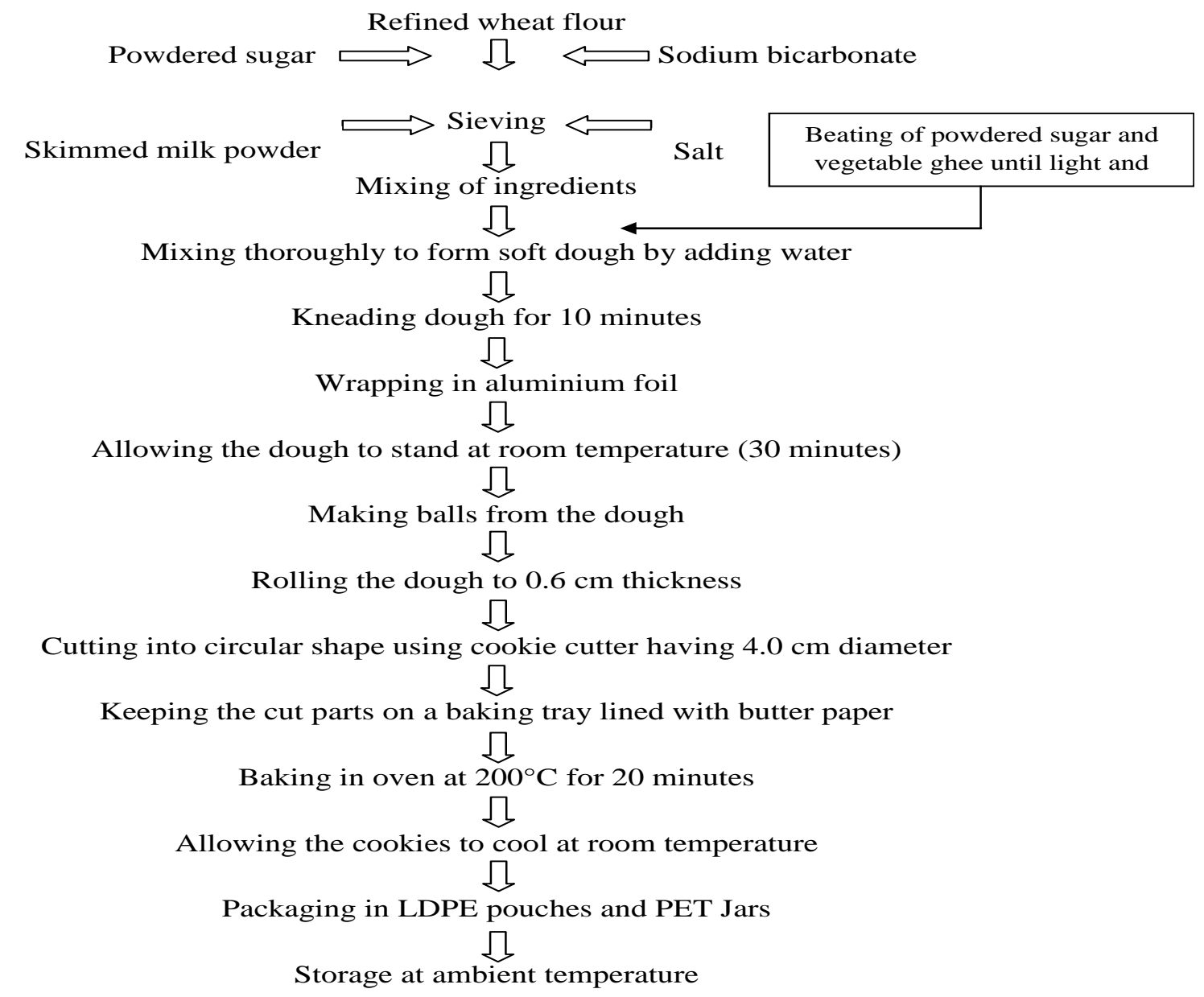


Fig.2 Sensory attributes of functionally enriched cookies

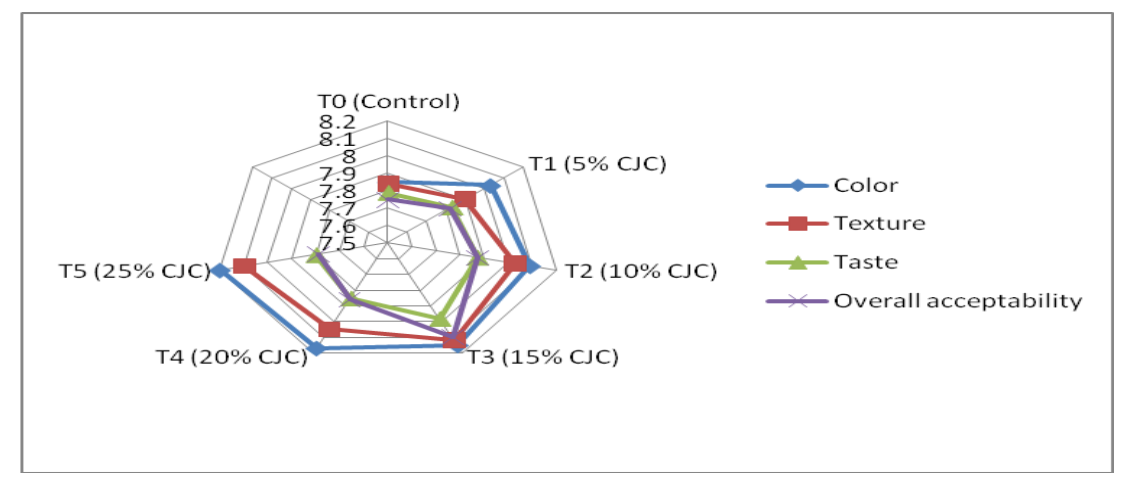

The moisture content and water activity was recorded as $4.28 \pm 0.11,0.40 \pm 0.02$ and 4.41 $\pm 0.09,0.44 \pm 0.01$ in $\mathrm{T}_{0}$ and $\mathrm{T}_{1}$, respectively. The ash content $(\%)$, crude protein and crude fat observed in cookies supplemented with carrot juice concentrate and refined wheat flour were $0.85 \pm 0.03,8.40 \pm 0.12,18.14 \pm$ 0.85 and $0.71 \pm 0.02,8.37 \pm 0.17,19.43 \pm$ 0.73 , respectively.

In conclusion the addition of carrot juice concentrate in cookies has resulted in improvement of sensory, nutritional and functional properties of the cookies. The functional cookies prepared by using 15 per cent carrot juice concentrate were optimized for better sensory characteristics. Carrot juice supplemented cookies contained higher amounts of ascorbic acid, total carotenoids, total phenolic content and antioxidant activity compared to standard cookies prepared with refined wheat flour. So, it was concluded that, carrot juice concentrate can successfully be utilized for the development of functional/health food products by way of supplementation and/or fortification. Hence, their availability in the market will definitely benefit the health conscious people and masses in general.

\section{References}

Aadil RM, Zeng XA, Han Z, and Sun DW. 2013. Effect of ultrasound treatments on quality of grapefruit juice. Food Chemistry, 14: 3201-3206.

Ahure D and Ejoha PO. 2020. Quality Evaluation of Cookies from Malted Sorghum (Sorghum bicolor), Sprouted Soybean (Glycine max) and Carrot (Daucus carota) Flour Blends. Asian Journal of Biotechnology and Bioresource Technology, 6: 14-27.

Amerine MA, Pangborn RM and Roessler EB. 1965. Principles of Sensory Evaluation of Food. In: Food Science and Technology: A Serious of Monographs. Academic Press, New York, London. Pp. 277-372.

Bakhru HK. 1993. Foods that Heal-The natural way to good health. Orient paper Backs, Delhi.

Banga O. 1957. Origin of the european cultivated carrot. Euphytica6: 54-63.

Brand-Williams W, Cuvelier ME and Berset C. 1995. Use of free radical method to evaluate antioxidant activity. Leben Wiss U Tech., 28: 25-30.

Breithaupt DE and Bamedi A. 2001. Carotenoid esters in vegetables and fruits: a screening with emphasis on $\beta$ cryptoxanthin esters. Journal of Agriculture and Food Chemistry49: 2064-2070.

Cho MR and Chung HJ. 2019. Quality characteristics and antioxidant activity of cookies added with purple carrot powder. Journal of the Korean Society 
of Food Culture 34: 612-619.

Cochran WG and Cox CN. 1967. Experimental designs. John wiley and sons, inc, New Delhi.

Dinnah A, Guyih MD and Eke MO. 2020. Vitamin Content and Storage Studies of Cookies Produced from Wheat, Almond and Carrot Flour Blends. Asian Food Science Journal, 15: 31-41.

Jeong SM, Kim SY, Kim DR, Jo, Nam K andAhn D. 2004.Effect of heat treatment on the antioxidant activity of extracts from citrus peels. Journal of Agriculture and Food Chemistry52: 3389-3393.

Kalra CL, Kulkarni SG, Berry SK. 1987.The carrot - a most popular root vegetable. Indian Food Pack41:46-73.

Kaur P, Ghoshal G and Jain A. 2018.Bioutilization of fruits and vegetables waste to produce $\beta$-carotene in solid-state fermentation; characterization and antioxidant activity. Process Biochemistry doi:10.1016/j.procbio. 2018.10.007.

Kumar N and Kumar K. 2011. Development of carrot pomace and wheat flour based cookies. Journal of Pure and Applied Science and Technology 1: 4-10.

Kumar N, Sarkar BC and Sharma HK. 2010. Development and characterization of extruded product using carrot pomace, pulse powder and rice flour. African Journal of Food Science, 4:703-717.

Mahony MO. 1985.Sensory evaluation of food. In: Statistical Methods and Procedures. Marcel Dekker Inc., New York.

Mazza, G. 1989. Carrots. In: N.A.M. Eskin (ed) Quality and Preservation of
Vegetables. CRC Press, Boca Raton FL, 75-119.

Mazzoni L, Perez-LopezP, Giampieri F, Alvarez-Suarez J, Gasparrini M, ForbesHernandez T and Battino M. 2016. The genetic aspects of berries: From field to health. Journal of the Science of Food and Agriculture96: 365-371.

Nagarajaiah BS and Prakash J. 2015.Nutritional composition, acceptability, and shelf stability of carrot pomace-incorporated cookies with special reference to total and $\beta$ carotene retention. Cogent Food and Agriculture 1: 1039886

Ranganna S. 2009. Handbook of analysis and quality control of fruit and vegetable products. $2^{\text {nd }}$ edn. Tata McGraw Hill Publishing Company Limited, New Delhi, India.

Sahni P and Shere DM. 2017. Physicochemical and sensory characteristics of carrot pomace powder incorporated fiber rich cookies. Asian Journal of Diary and Food Research 36: 327-331.

Sharma KD, Karki S, Thakur NS andAttri S. 2012. Chemical composition, functional properties and processing of carrot-a review. Journal of Food Science and Technology49:22-32.

Ukeyima MT, Dendegh TA andOkeke PC. 2019. Effect of Carrot Powder Addition on the Quality Attributes of Cookies Produced from Wheat and Soy Flour Blends. Asian Food Science Journal, 10: 1-13.

Wrolstad RE. 2004. Anthocyanin pigments bioactivity and coloring properties. Journal of Food Science, 69: 419-421.

\section{How to cite this article:}

Sakshi Sharma and Sharma, K. D. 2020. Development of Carrot Juice Concentrate Enriched Functional Cookies. Int.J.Curr.Microbiol.App.Sci. 9(12): 3129-3135. doi: https://doi.org/10.20546/ijcmas.2020.912.372 